\title{
Efficient Finite Element Models for Calculation of the No-load Losses of the Transformer
}

\author{
Kamran Dawood ${ }^{a *}$, Mehmet Aytac Cinar ${ }^{b}$, Bora Alboyacl $^{c}$, Olus Sonmez $^{d}$ \\ ${ }^{a, c}$ Department of Electrical Engineering, Kocaeli University, Izmit, Kocaeli, Turkey \\ ${ }^{b}$ Izmit Vocational School, Kocaeli University, Kartepe, Kocaeli Turkey \\ ${ }^{d}$ Sonmez Transformator A.S., Gebze, Kocaeli, Turkey \\ ${ }^{*}$ E-mail address: kamransdaud@yahoo.com \\ ORCID numbers of authors:

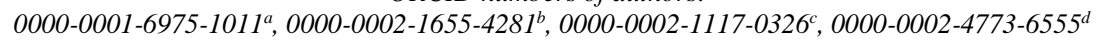

Received date: May 2017

Accepted date: August 2017

\begin{abstract}
Different transformer models are examined for the calculation of the no-load losses using finite element analysis. Twodimensional and three-dimensional finite element analyses models are used for the simulation of the transformer. Results of the finite element method are also compared with the experimental results. The results show that 3-dimensional model provides high accuracy as compared to the 2-dimensional models. However, the 2-dimensional half model is the less timeconsuming method as compared to the 3 and 2-dimensional full models. Simulation time duration taken by the different models of the transformer is also compared. The difference between the 3-dimensional finite element method and experimental results are less than 3\%. These numerical methods can help transformer designers to minimize the development of the prototype transformers.
\end{abstract}

Keywords: Core losses, Design optimization, Finite element analysis, Iron losses, No-load losses, Power transformer.

\section{Introduction}

Electrical energy is one of the most important factors for socio-economic growth [1]. Electrical energy is transmitted to consumers after the processes of generation, transmission, and distribution [2]. Stability of the electrical power system mainly depends on the working of the transformer. The efficiency of the distribution transformers is between 98 and 99 percent [3]. Even with the $98 \%$ of the efficiency, distribution transformers cause the major loss in the distribution system because transformers work all the 24 hours of the day and even $2 \%$ of energy loss can cause significant financial damage to the electric providers. There are two main types of losses in the transformer i.e. load losses and no-load losses.

Load losses are also known as copper losses. These losses are mainly due to the absorption of the active power by the transformer while carrying rated current in the winding. These losses are also known as short circuit losses because, during the calculation of the load losses, secondary windings remain short-circuited.

No-load losses are also known as iron or constant losses. No-load losses are initiated by the magnetization current, which is required to energize the core of the transformer. Iron losses are independent of the load losses. For no-load losses rated voltage is applied to the primary winding and the secondary winding remains open circuit. The no-load losses include the eddy current loss, the 
hysteresis loss, and the dielectric loss [4-6]. $I^{2} R$ losses are negligible for the no-load losses because during the open circuit, current is very small as compared to the short-circuit current.

$$
\mathrm{P}_{\text {no-load }}=\mathrm{P}_{\mathrm{e}}+\mathrm{P}_{\mathrm{h}}+\mathrm{P}_{\mathrm{d}}
$$

Eddy current and hysteresis losses contribute almost $99 \%$ of the iron losses. These two components could be extracted as [7];

$$
\begin{aligned}
& \mathrm{P}_{\mathrm{h}}=\mathrm{k}_{\mathrm{h}} f \mathrm{~B}^{\mathrm{n}} \\
& \mathrm{P}_{\mathrm{e}}=\mathrm{k}_{\mathrm{e}} f^{2} \mathrm{~B}^{2}
\end{aligned}
$$

No-load losses also depend on the construction of the core. Magnetic induction is not constant on the different parts of the core, thus power losses also vary locally depending on the Eq. (2) and Eq. (3), on the transformer core. Therefore, accurate calculation and minimization of the no-load losses are one of the most difficult challenges for the transformer designers [8].

Finite element method is one of the most efficient numerical methods for the calculation of no-load and load losses of the transformers [7]. In [9] and [10], no-load losses were analyzed and compared with different grade core materials. Due to the electromagnetic parameters of the materials, finite element analysis provides easiness with high accuracy. Stray losses occurred in the different parts of the transformer, such as core clamps, walls, and top-plates of the tank, etc., can be calculated easily using FEA [11, 12, 13]. Similarly, efficiencies of different shielding and shunting applications for losses caused by leakage fluxes were defined in $[14,15,16]$. In all these studies, one of the main drawbacks is to model the studied transformer and its components accurately. While coarse modeling increases the relative error of the results, but excessive details in modeling increases the solution time.

The main objective of this study is to compare the different numerical models for the calculation of the no-load losses. 3-dimensional and 2-dimensional finite element analyses models are used for the calculation of the no-load losses. Simulation results are also compared with the experimental measurements.

\section{Studied transformer}

$1250 \mathrm{kVA}, 50 \mathrm{~Hz}, 34.5 / 0.4 \mathrm{kV}$ three phase transformer with Dyn connected windings is used in this study. The material of the M5 grain oriented silicon steel was used in the manufacturing of the core. The core induction was chosen as $1.53 \mathrm{~T}$ in the design stage. Main parameters of the transformer are given in Table 1. Fig. 1 shows the front view of the transformer. 


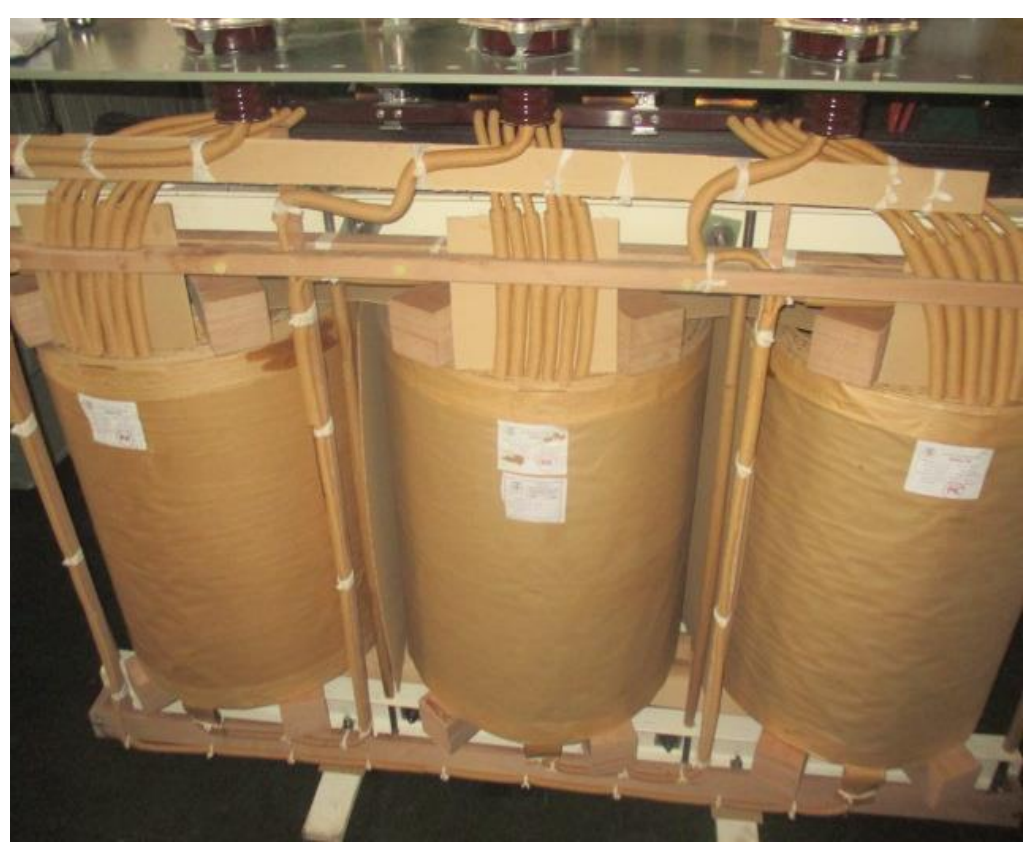

Fig. 1. Front view of the studied transformer

Table 1. Transformer Data

\begin{tabular}{l|ll}
\hline \multirow{4}{*}{ Ratings } & Power (kVA) & 1250 \\
& High Voltage (kV) & 34.5 \\
& Low Voltage (kV) & 0.4 \\
& HV Current (A) & 12.08 \\
& LV Current (A) & 1804.37 \\
& No-load losses (W) & 1750 \\
& Frequency (Hz) & 50 \\
\hline \multirow{2}{*}{ Core } & Material & M5 \\
& Nominal Flux Density & 1.53 \\
\hline \multirow{3}{*}{ Windings } & Material & Aluminum \\
& HV Turns & 2390 \\
& LV Turns & 16 \\
\hline
\end{tabular}

Hysteresis and power loss curves of core material are given in Fig. 2 and Fig. 3. Fig. 4 shows the magnetization curves of the core material for different induction values. 


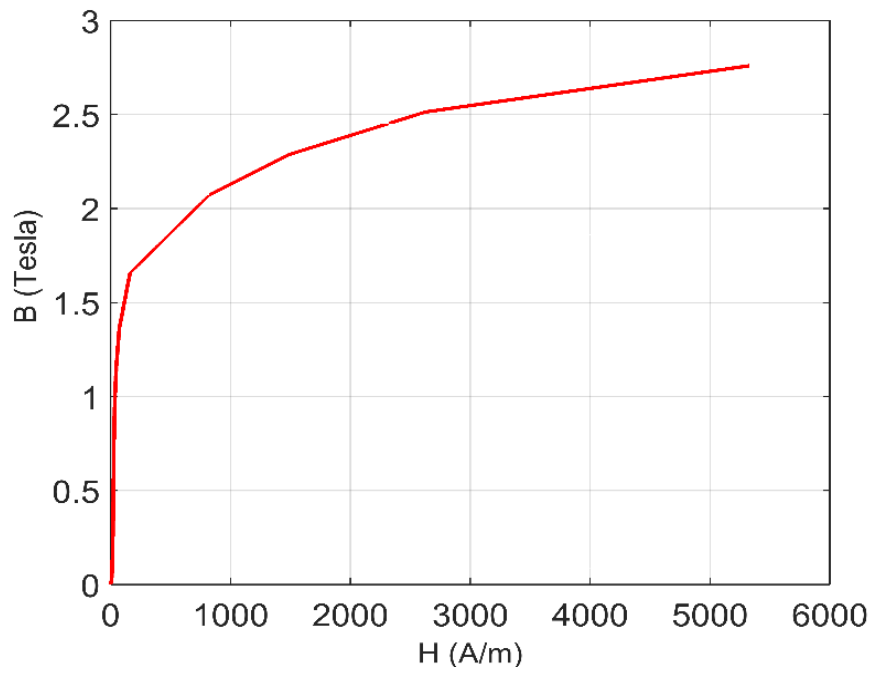

Fig. 2. B-H curve of the transformer [17]

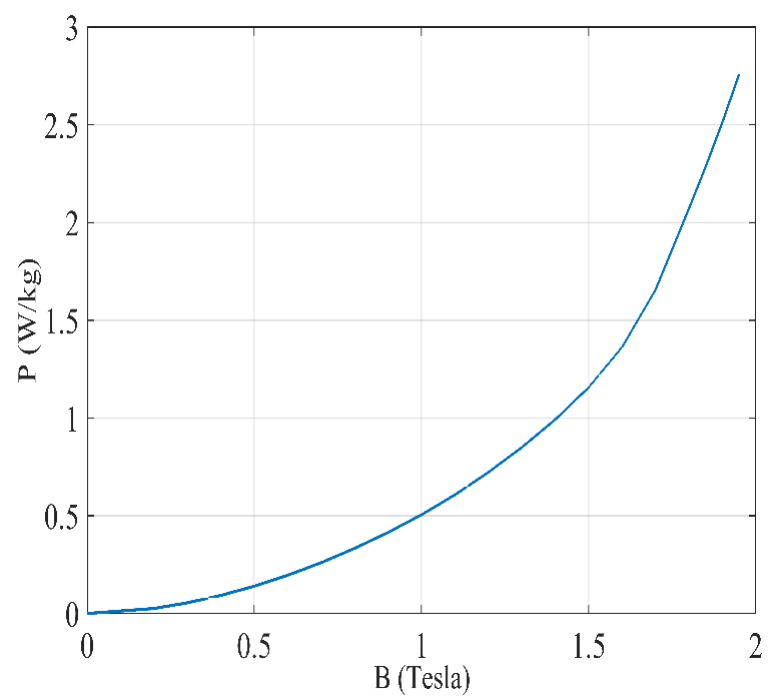

Fig. 3. B-P curve of the transformer [17]

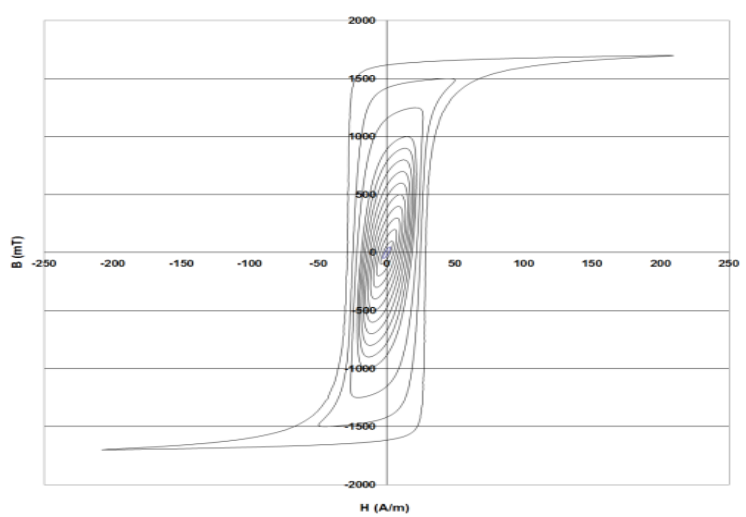

Fig.4. Magnetization curves of the core material [17] 


\section{FEM based no-load losses computation}

Finite element methods are versatile and most commonly used numerical method among researchers and practitioners to solve complex problems in engineering and science [18]. FEM is a numerical technique which commonly used for the simulation of differential and integral equations. FEM is mostly used to determine the electromagnetic, magnetostatic, and thermal characteristics of the materials. In this study, no-load losses of the transformer are calculated by using ANSYS Maxwell finite element analysis software.

Fig. 5, Fig. 6 and Fig. 7 show the 3-D full model, 2-D full model and 2-D half model of the studied transformer under mesh operation. The total number of the mesh generated in the 3-D full model is 40369 elements, 2-D full model is 1551 and a total number of the mesh generated in the 2-D half model is 780 elements.

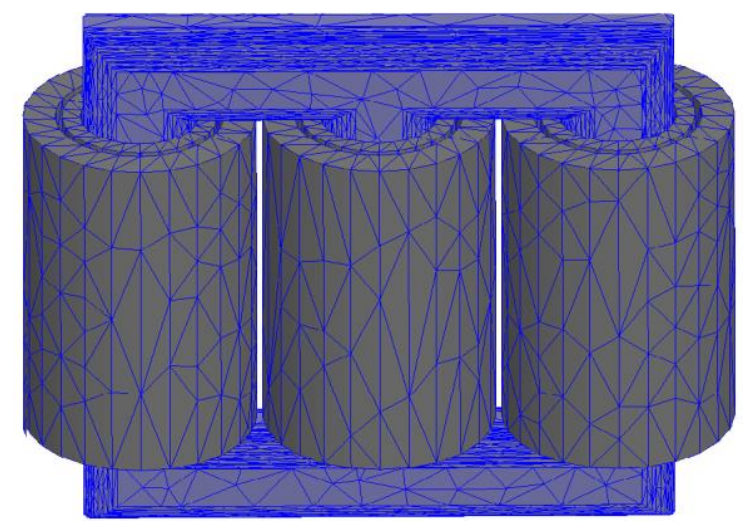

Fig. 5. Mesh operation of 3-D full model of the transformer

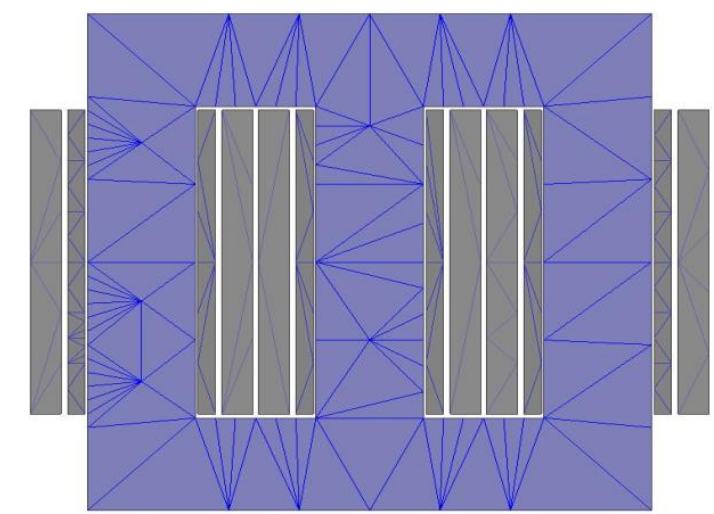

Fig. 6. Mesh operation of 2-D full model of the transformer

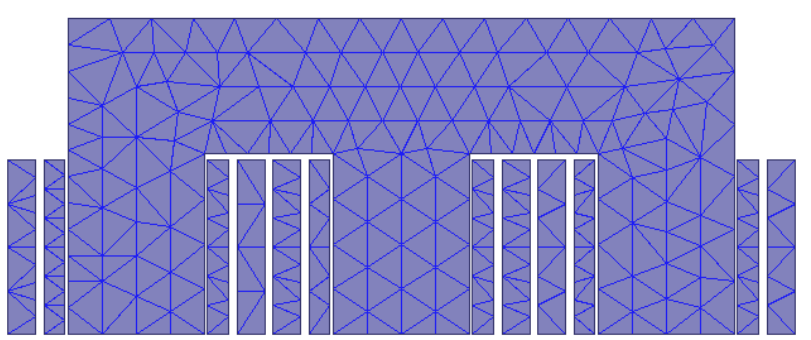

Fig. 7. Mesh operation of 2-D half model of the transformer 
Transient analysis is performed for the calculation of the no-load losses and flux distribution. Fig. 8 shows the external excitation circuit of the transformer using Maxwell Circuit Editor.
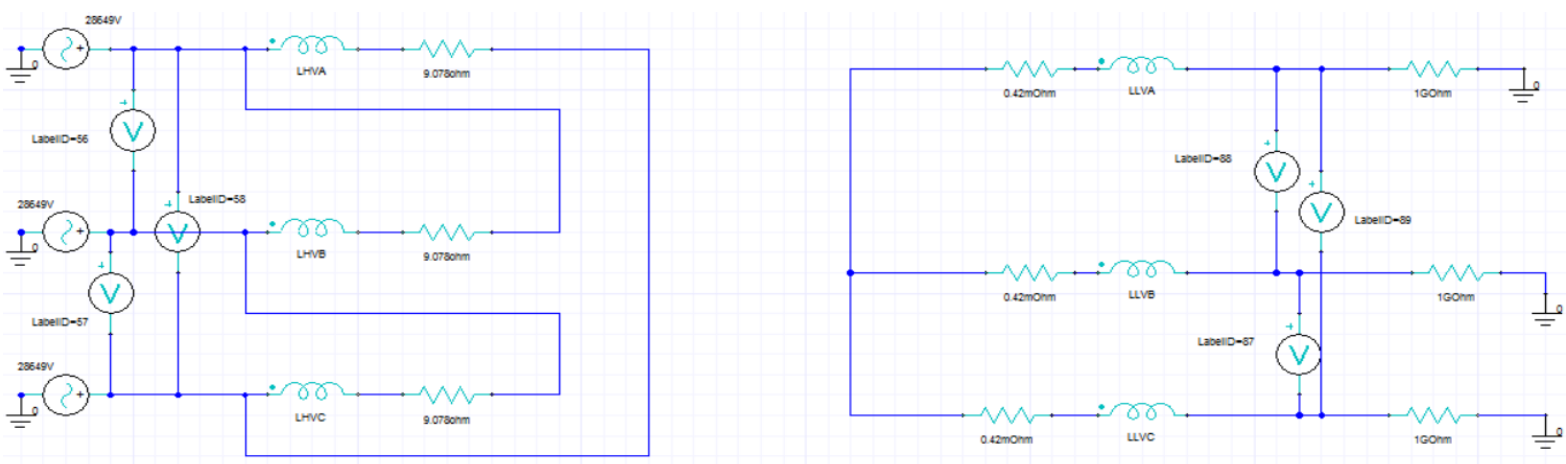

Fig. 8. External excitation circuit of three-phase transformer

The induced voltage in the low voltage and high voltage windings are shown in Fig. 9 and Fig. 10.

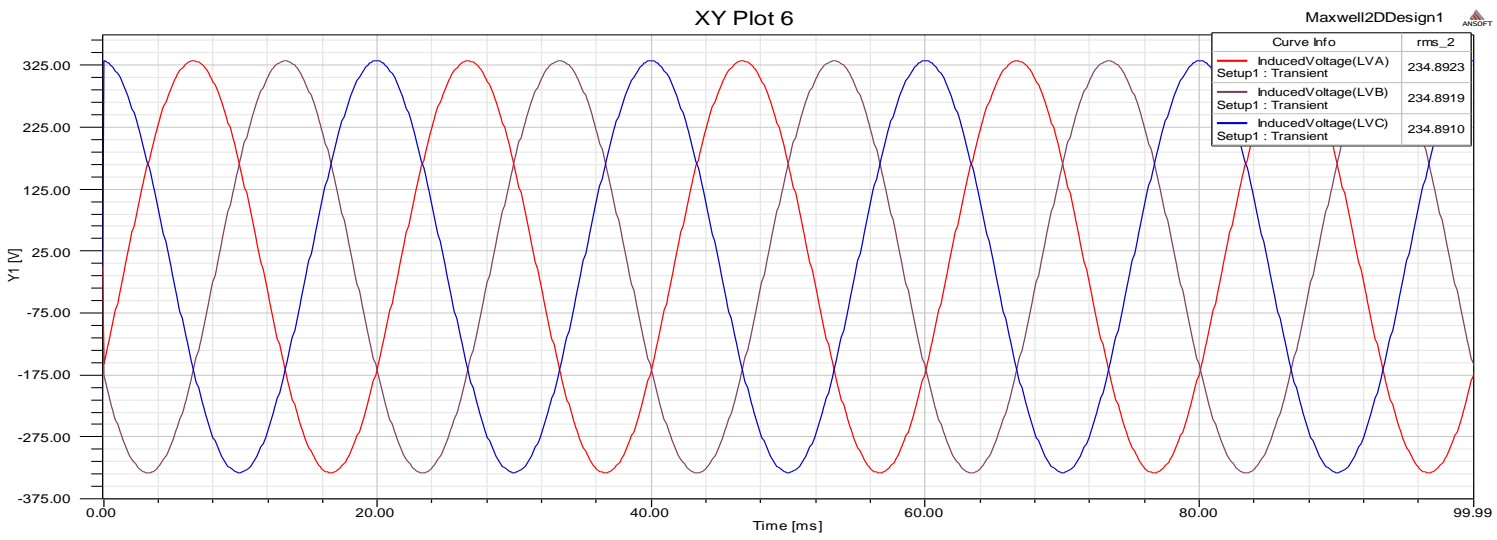

Fig. 9. Induced voltage in low voltage windings

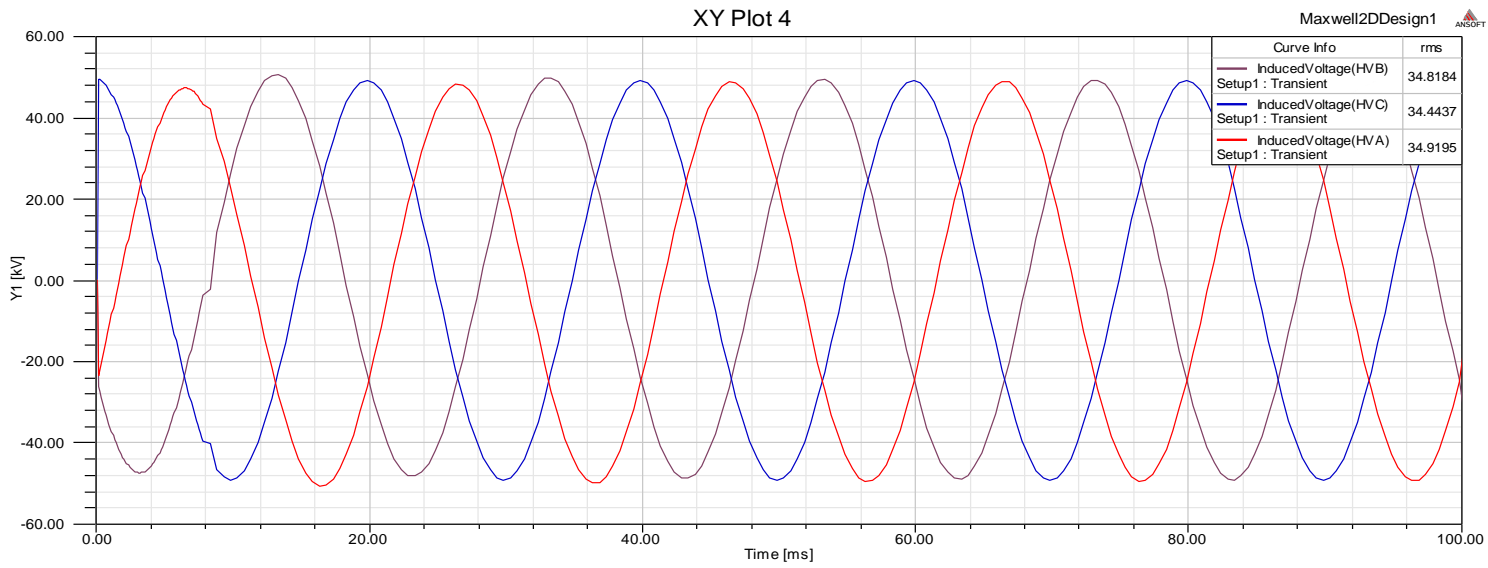

Fig. 10. Induced voltage in high voltage windings

Distribution of the magnetic flux density of the 3-D full, 2-D full and 2-D half model of the transformer are shown in Fig. 11, Fig. 12 and Fig. 13 respectively. 


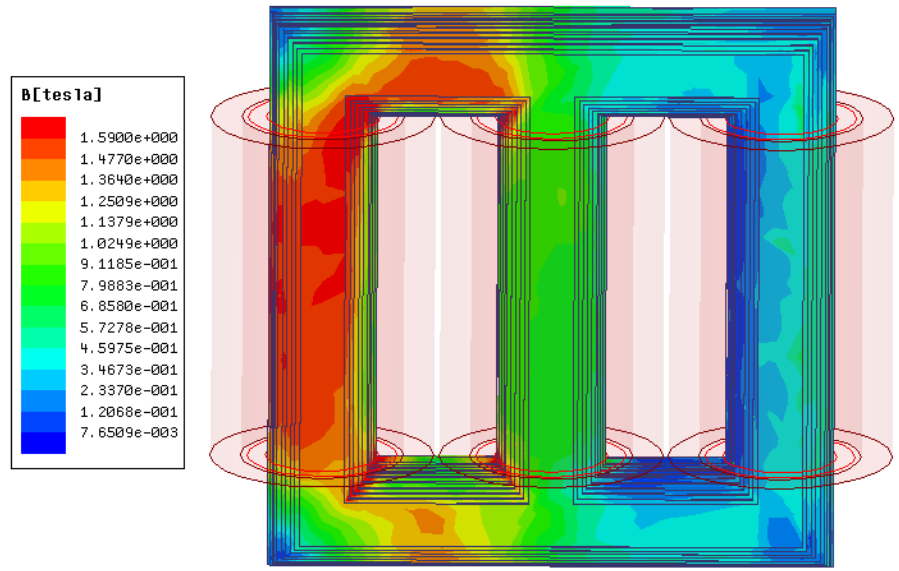

Fig. 11. Magnetic flux density distribution of 3-D full model

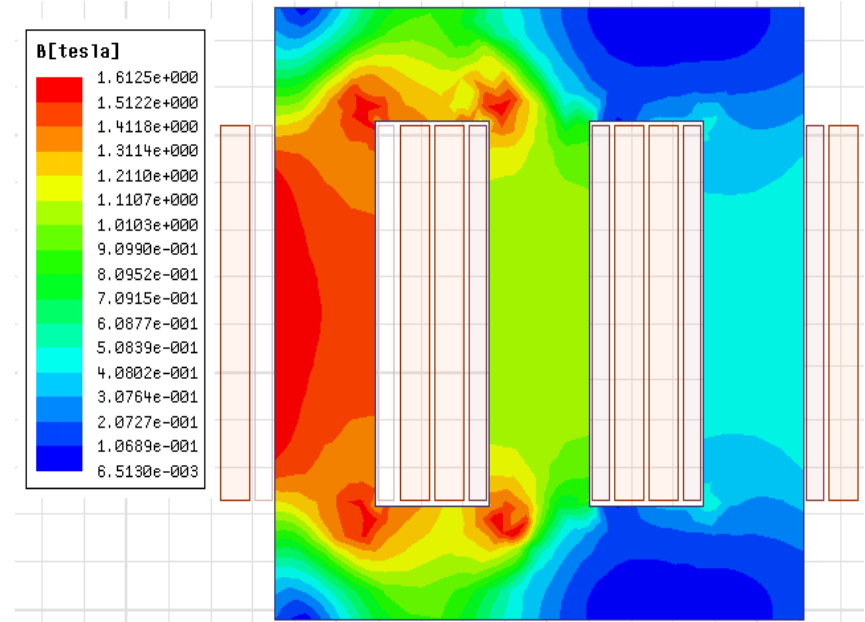

Fig. 12. Magnetic flux density distribution of 2-D full model

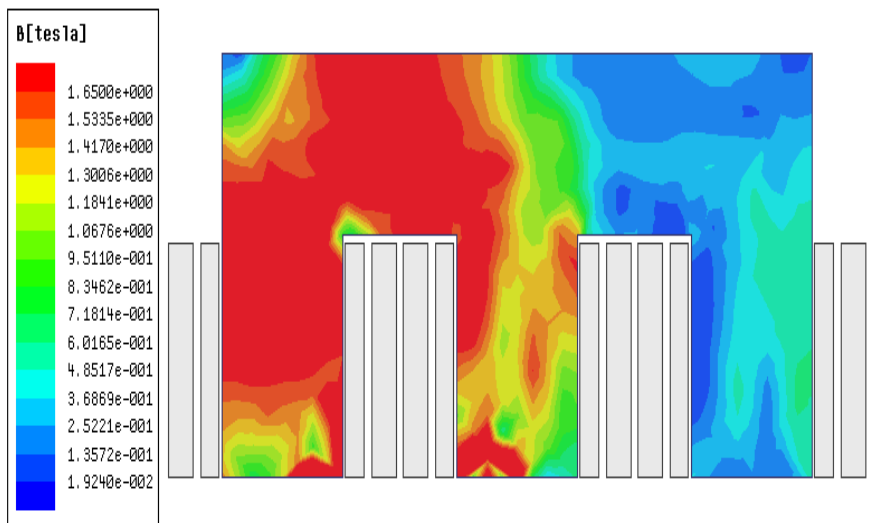

Fig. 13. Magnetic flux density distribution of 2-D half model 


\section{Results and discussion}

Obtained results of both experimental and simulation studies are compared, depending on the power losses and solution time. No-load losses vs. time variations obtained from the analyses of 3-D full model, 2-D full model and 2-D half-model are given in Figs. 14-16, respectively. All simulations were performed on the same computer.

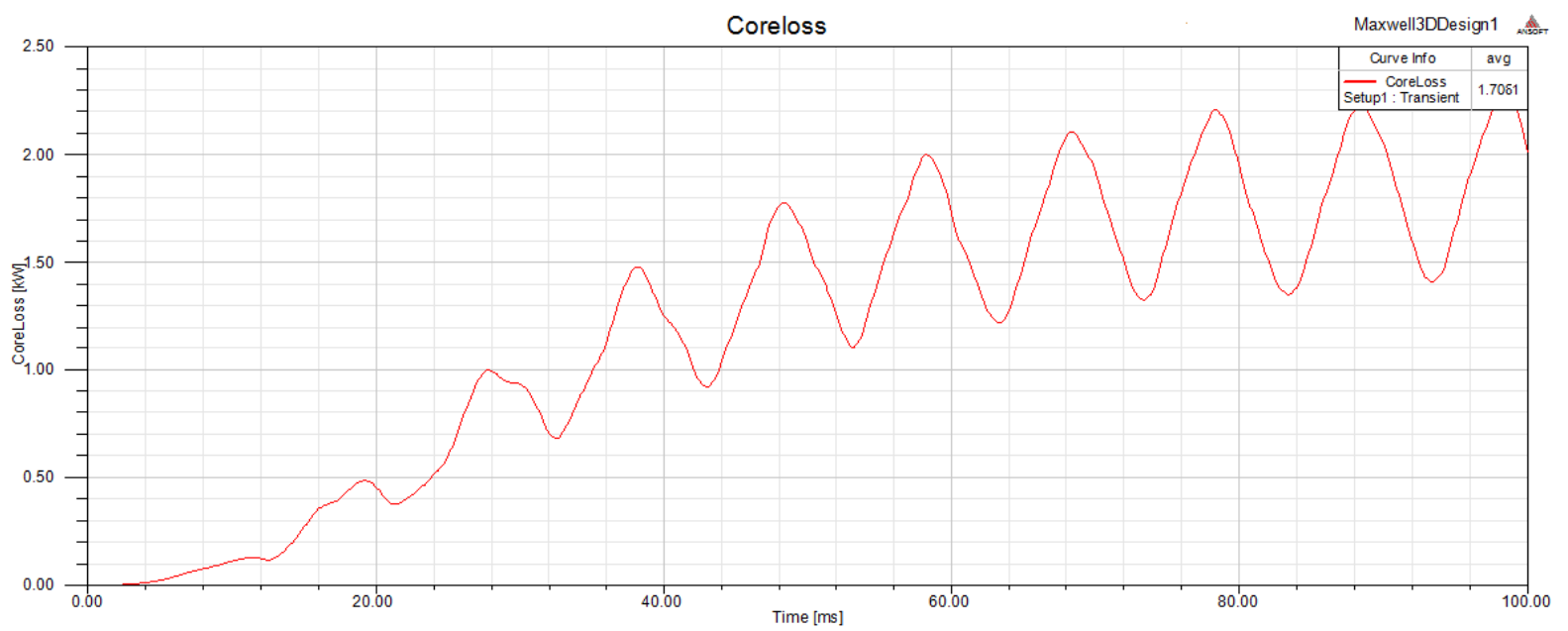

Fig. 14. No-load losses using 3-D full model

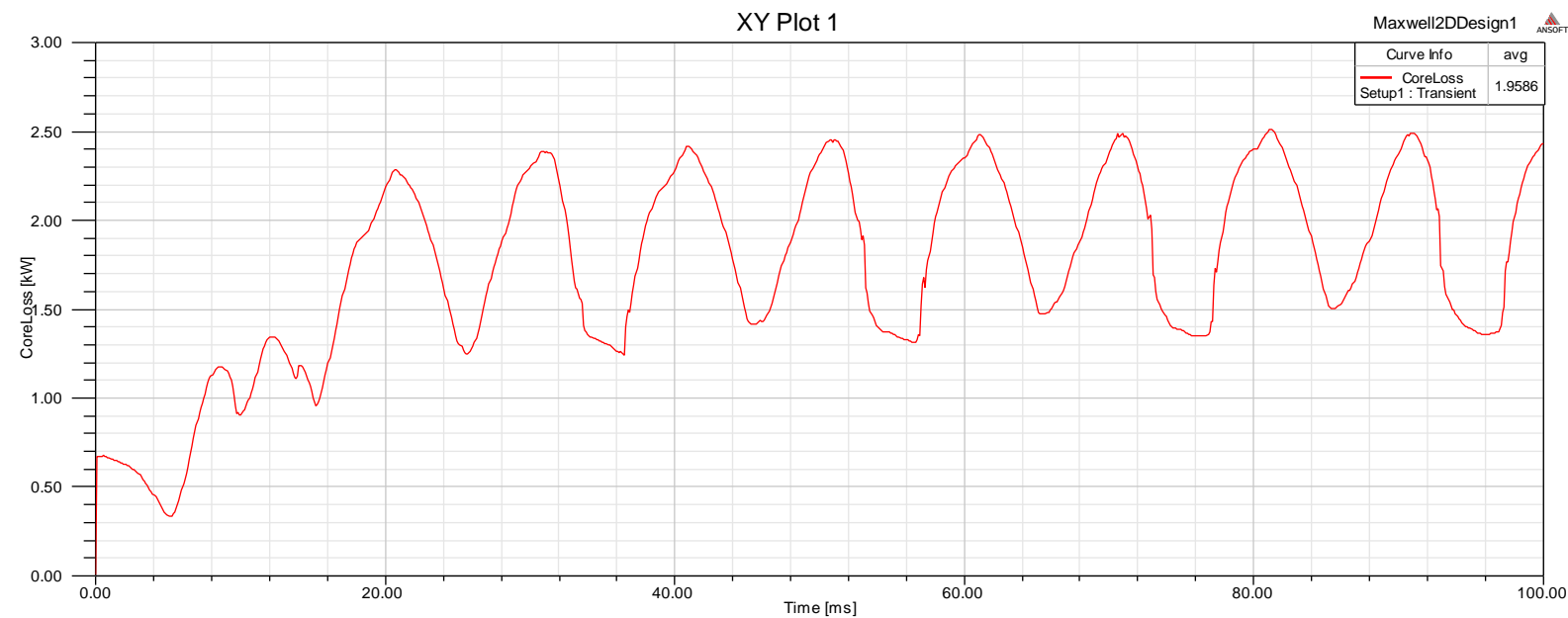

Fig. 15. No-load losses using 2-D full model 


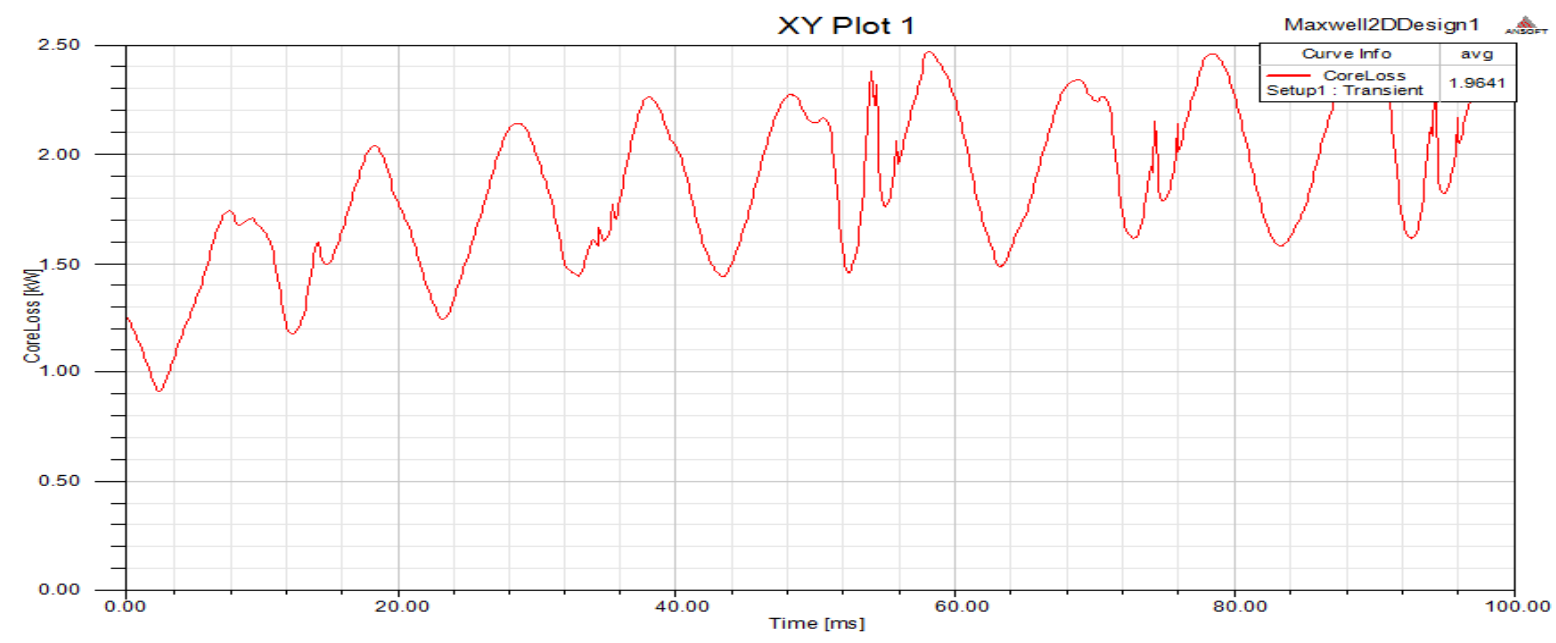

Fig. 16. No-load losses using 2-D half model

Experimental test and measurements were realized in the test laboratory of the manufacturer. Measurement of no-load losses, which is a part of the routine tests, was realized depending on the requirements of IEC 60076-1. Rated voltage was applied to the HV windings, where LV windings were open-circuited. For voltage, current and power loss measurements, a-eberle PQ-Box 200 power analyzer were used.

Comparison of the obtained simulation results and experimental measurements are given in Table 2 .

Table 2. No-load losses of Power Transformer

\begin{tabular}{lccc}
\hline \multicolumn{1}{c}{ Approach } & No-Load Losses & Simulation Time & Relative Error (\%) \\
\hline Experimental method & $1750 \mathrm{~W}$ & - & - \\
3-Dimensional full Model & $1706 \mathrm{~W}$ & 1233 Minutes & 2.6 \\
2-Dimensional full Model & $1958 \mathrm{~W}$ & 48 Minutes & 11.88 \\
2-Dimensional half Model & $1964 \mathrm{~W}$ & 23 Minutes & 12.22 \\
Analytical method & $1825 \mathrm{~W}$ & - & 4.29 \\
\hline
\end{tabular}

Results show that the 3-dimensional method is more accurate as compared to the other methods however, 3-D full model consumes more simulation time as compared to the other methods.

As shown in Fig. 14 the no-load losses during the simulation of the 3-D full model of the transformer is $1706 \mathrm{~W}$. The percentage difference between the 3-D full model and experimental result is $2.6 \%$. Fig. 15 shows the no-load losses during the simulation of the 2-D full model of the transformer and relative error between 2-D full model and experimental result is $11.88 \%$. The percentage difference is higher in 2-D full model as compared to the 3-D full model. However 2-D full model consumes less time as compared to the 3-D full model. Fig. 16 shows the no-load losses during the simulation of the 2-D half model and the percentage difference between the 2-D half model and experimental result is $12.22 \%$. The percentage difference between the analytical and experimental method is $4.29 \%$.

\section{Conclusion}

This paper investigates the accuracy of different models of the numerical methods for the calculation of the no-load losses of the transformer. No-load losses are calculated by using analytical method and 
finite element analysis software. Results are also compared with the experimental results. Results show that the 3-dimensional model is more accurate as compared to the 2-D models. No-load loss is one of the important factors for the transformer designers and these models can help the transformer designers to calculate no-load losses accurately.

\section{Acknowledgement}

The authors express their gratitude to the Sonmez Transformer Company (STS) of Turkey for providing financial support and practical data of the transformer.

\section{Notations}

$\begin{array}{ll}\text { 2-D } & \text { Two Dimensional } \\ 3-\mathrm{D} & \text { Three Dimensional } \\ \mathrm{B} & \text { Induction } \\ f & \text { Frequency } \\ \text { FEA } & \text { Finite Element Analysis } \\ \mathrm{FEM} & \text { Finite Element Method } \\ \mathrm{HV} & \text { High Voltage } \\ \mathrm{I} & \text { Current } \\ \mathrm{k}_{\mathrm{e}} & \text { Eddy current loss co-efficient } \\ \mathrm{k}_{\mathrm{h}} & \text { Hysteresis current loss co-efficient } \\ \mathrm{LV} & \text { Low Voltage } \\ \mathrm{n} & \text { Steinmetz co-efficient } \\ \mathrm{P}_{\mathrm{no}}-\text { load } & \text { No-load losses } \\ \mathrm{P}_{\mathrm{e}} & \text { Eddy current loss } \\ \mathrm{P}_{\mathrm{h}} & \text { Hysteresis loss } \\ \mathrm{P}_{\mathrm{d}} & \text { Dielectric loss } \\ \mathrm{R} & \text { Resistance }\end{array}$

\section{References}

[1] Dawood, K., Hybrid wind-solar reliable solution for Turkey to meet electric demand, Balkan Journal of Electrical and Computer Engineering, 4(2), 62-66, 2016.

[2] Çakı1 , T , Carlak, H, Özen, Ş., Modeling of power network system of the high voltage substation: a simulation study, International Journal Of Engineering \& Applied Sciences, 7(3), 39-57, 2015.

[3] Keulenaer, D.H., Chapman, D., Fassbinder, S., The scope for energy saving in the EU through the use of energy-efficient electricity distribution transformers,. 16th International Conference and Exhibition on Electricity Distribution, 4(1), 4-27, London, 1999.

[4] Olivares, G.J.C., Escarela, P.R., Georgilakis, P. S., Campero, L.E., Separation of no-load losses for distribution transformers using experimental methods: Two frequencies and two temperatures, 7th Mediterranean Conference on Power Generation, Transmission, Distribution and Energy Conversion, Agia Napa, Cyprus, 2010.

[5] Feinber R., Modern Power Transformer Practice, The Macmillan Press, Great Britain, 1979.

[6] Georgilakis, P., Hatziargyriou, N., Paparigas, D., AI helps reduce transformer iron losses, IEEE Computer Applications in Power, 12(4), 41-46, 1999.

[7] Dawood. K., Çok sargılı transformatörler için kisa devre empedansı ve sarglara etkiyen kuvvetlerin belirlenmesi için yeni bir yaklaşım, M.S. thesis, Department of electrical engineering Kocaeli University., Kocaeli, Turkey, 2017.

[8] Allan, D.J., IEE Power Division: Chairman's address. Power transformers - the second century, Power Engineering Journal, 5(1), 5-14, 1991. 
[9] Kefalas, T.D., Kladas, A.G., Mixed Si-Fe Wound Cores Five Legged Transformer: Losses and Flux Distribution Analysis, IEEE Transactions on Magnetics, 48(4), 1609-1612, 2012.

[10]Hernandez, I., Olivares-Galvan, J.C., Georgilakis, P.S., Canedo, J., A Novel Octagonal Wound Core for Distribution Transformers Validated by Electromagnetic Field Analysis and Comparison With Conventional Wound Core, IEEE Transaction on Magnetics, 46(5), 1251-1258, 2010.

[11] Kim, Y. J., Lee, J. D., Ahn, H. M., \& Hahn, S. C., Numerical Investigation for Stray Loss Analysis of Power Transformer, International Conference on Electrical Machines and Systems, Busan, South Korea, 2013.

[12]L. Kralj ve D. Milijavec, Stray losses in power transformer tank walls and construction parts, International Conference on Electrical Machines, Rome, Italy, 2010.

[13] Vega, M. V., Perez, R. E., Niewierowicz, T., 3D Finite Element Estimation of Stray Losses in Three-Phase Transformers, Journal of Applied Computer Science, 16(1), 89-99, 2008.

[14] Susnjic, L., Haznadar, Z., Valkovic, Z., 3D finite-element determination of stray losses in power transformer, Electric Power Systems Research, 78(10), 1814-1818, 2008.

[15] Milagre, A.M., Ferreira, M.V., Cangane ,G.M., Komar, A., Avelino, P.A., 3D Calculation and Modeling of Eddy Current Losses in a Large Power Transformer, International Conference on Electrical Machines, Marseille, France, 2282-2286, 2012.

[16] Mokkapaty, S. P. K., Weiss, J., Schramm, A., Magdaleno-Adame, S., Schwarz, H., OlivaresGalvan, J.C., 3D Finite Element Analysis of Magnetic Shunts and Aluminum Shields in Clamping Frames of Distribution Transformers, IEEE International Autumn Meeting on Power, Electronics and Computing, Ixtapa, Mexico, 1-6, 2015.

[17]Dawood, K., Alboyaci, B., Cinar, M. A., Sonmez, O., A new method for the calculation of leakage reactance in power transformers, Journal of Electrical Engineering and Technology, 12(5), 1883-1890, 2017.

[18]Karakaş, A , Daloğlu, A ., Shear and volumetric locking effect on the performance of harmonic solid ring finite elements, International Journal Of Engineering \& Applied Sciences, 7(1), 68-85, 2015. 